\title{
Determination of flammability parameters for organic waste resulting from the processing of sunflower seeds
}

\author{
Andrei Szollosi-Moța ${ }^{1 *}$, Maria Prodan ${ }^{1}$, Vasilica Irina Nălboc $^{1}$, and Niculina Sonia Șuvar ${ }^{1}$ \\ ${ }^{1}$ National Institute for Research and Development for Mine Safety and Protection to Explosion \\ INSEMEX Petrosani, 32-34 G-ral Vasile Milea Street, Petrosani, Romania
}

\begin{abstract}
Agricultural waste is found in abundance in the environment, whether it is the plant itself represented by the stem, leaf or seeds that have been peeled or other waste. By drying and crushing the residues from the plants, organic powders will be formed with a variable granulation and humidity. Through the processing of oilseeds such as sunflower seeds, significant amounts of waste from seeds result. Seed shells resulting from technological processes crumble, forming fine powders, whose granulations are different. A certain percentage will be $63 \mu \mathrm{m}$ or smaller and if those fine powders are mixed with air can form clouds with explosive properties. The purpose of this paper was to determine the minimum ignition layer and cloud temperatures. Experimental determination of flammability parameters is particularly important in order to take the proper safety measures so that accidents can be avoided.
\end{abstract}

\section{Introduction}

Ignition and self-ignition of solid materials can be considered a transient phenomenon, which depends on temperature, heating and self-heating conditions and heat accumulation. Conditions for initiating the combustion process are limited, in particular by the concentration of fuel and oxygen and the source of ignition (flame, radiant heat, spark, etc.)[2]. The methods for determining the capacity of flammable materials are based on the determination of the limit conditions under which ignition or self-ignition is observed.

The ignition source of a given fuel system can be an object or a substance that is a certain temperature and is able to transmit the required amount of energy from a certain type for a certain period of time. Ignition energy is supplied to the fuel mixture by an external ignition source. Therefore, it is called "external" ignition [7,8].

Explosions and fires caused by dust are some of the most significant threats in many industries where layers of dust and clouds are formed as a result of technological processes, which are capable of ignition. Flammable dusts can be a fire hazard after settling on hot surfaces. Sunflower waste comes from the industrial processing of sunflower seeds in order

\footnotetext{
${ }^{*}$ Corresponding author: andrei.szollosi@insemex.ro
} 
to obtain oils. The chemical composition of some types of organic powders can be found in table no. 1 .

Table 1. The chemical composition of sunflower powder.

\begin{tabular}{|c|c|c|c|c|}
\hline Margin & Material & Cellulose & Lignin & Hemicellulose \\
\hline No & Corn straw & 48,6 & 15,1 & 21,3 \\
\hline 1. & Wood & $35-50$ & $25-30$ & $20-30$ \\
\hline 2. & Tea waste & 30,2 & 40 & 19,9 \\
\hline 3. & Oat straw & $35-39$ & $10-15$ & $20-26$ \\
\hline 4. & Sunflower & 23,47 & 17 & 34,6 \\
\hline 5. & Corn straw & 48,6 & 15,1 & 21,3 \\
\hline
\end{tabular}

Combustible dust, as defined by OSHA, is a solid material composed of distinct particles or pieces, regardless of size, shape or chemical composition, which may present a fire or explosion hazard when suspended in air or other environment oxidizing on a range of concentrations ". The presence of this dust, both in open and unseen areas, can present a serious danger to employees, employers and installations, as explosions of fires can be catastrophic in nature $[4,5]$. Vulnerable industries to fire or dust explosion include, but are not limited to, agriculture, chemicals, food (sugar, candy, spices, starch, flour and feed), cereals, fertilizers, tobacco, plastics, wood, forest, paper, pulp, rubber, furniture, textiles, pesticides, pharmaceuticals, tire and rubber manufacturers, dyes, coal, metalworking (aluminium, chromium, iron, magnesium and zinc), recycling and coal operations. Given this long list of vulnerable industries, combined with the fact that many companies cannot adequately identify a fuel dust threat, OSHA suggests completing a thorough dust hazard assessment covering the following areas:

- Materials that can be combustible;

- Processes that use any combustible dust;

- Open and especially hidden areas, where dust can collect;

- Opportunities that can cause air dust in the air;

- Any ignition source $[4,5]$.

The key to risk assessment is to correctly identify whether or not the dust is really combustible. National Fire Protection Association (NFPA) 654: Standard for the prevention of explosions against fire and dust in the manufacture, processing and handling of combustible particulate solids and NFPA 454: Standard for combustible metals, metallic powders and metallic dusts both define combustible dust as "any fine solid material having a diameter of 420 microns or less that presents a fire or explosion hazard when dispersed and ignited in air". Other variables to consider, in addition to particle size, are how the dust will be dispersed, what kind of ventilation is available, air currents, ignition sources and the presence of physical barriers that ensure the confinement of dust or that ensure the separation of work processes. Control and elimination of combustible dust is also essential $[1,3]$.

The most important and often reported in the literature explosive parameters for combustible dusts are, according to the series of standards SR EN 14034-1,2,3: Determination of explosion characteristics of powder clouds, [7]:

Maximum explosion pressure Pex - the highest overpressure that occurs during an explosion of a powder mixture in a closed vessel; 
Maximum pressure rise rate $(\mathrm{dP} / \mathrm{dt})$ max - the maximum value of the pressure increase per unit time during explosions [77], for all explosive atmospheres in the explosive range of combustible substances in a closed vessel under the specified test conditions and atmospheric conditions standard;

Severity factor - Kmax, Kst volume independent characteristic that is calculated using the cubic equation:

$$
\left(\frac{\mathrm{dP}}{\mathrm{dt}}\right)_{\max } \cdot \mathrm{V}^{\frac{1}{3}}=\text { const. }=\mathrm{K}_{\mathrm{st}}=\mathrm{K}_{\max } ;
$$

Minimum explosion concentration or lower explosion limit (CmEx, LIE or LEL) - the minimum concentration of combustible dust mixed with air at which the explosion no longer occurs;

Minimum ignition energy MIE - the lowest electrical energy stored in a capacitor which at discharge is sufficient to produce an ignition of the most flammable mixture of a given powder under specific test conditions;

Minimum ignition temperature of a cloud of dust MIT - the lowest temperature of a hot surface at which self-ignition of a cloud of dust occurs under specified test conditions;

Minimum ignition temperature of the LIT powder layer - the lowest temperature of a hot surface at which a powder layer with a specified thickness is ignited deposited on this hot surface;

The values of these parameters can be found in the literature or in online databases, but these values should be seen as indications and not as a basis for the design of safety measures in industry, which should be based on specific data for each powder in part.

The minimum amount of energy that can ignite a flammable mixture is called the minimum ignition energy. Minimum ignition energy is one of the most important safety parameters for the prevention of uncontrolled explosions.

For a flammable mixture within the explosion limits to be ignited, the most important criterion that must be met is the existence of a minimum ignition energy. For this reason the reported energies for most gases are those determined at the stoichiometric concentration. The energies required to ignite mixtures within the explosion range are much higher than the minimum ignition energy determined at the stoichiometric concentration. $[9,10]$

Minimum ignition energy is a particularly important parameter for safety standards but also for understanding the process of initiating explosive mixtures. The minimum ignition energies for most gaseous hydrocarbons are very small $(0.2-0.3 \mathrm{~mJ})$. Measuring such low energies is very difficult. Initiation with sparks, lasers and heated wire are just some of the techniques used to determine this energy. [6]

The initiation with electric sparks has been studied by many authors and is the subject of a standard for its determination, namely the American standard ASTM E 582 1988. The electric discharge used in an experiment can be measured to estimate the amount of energy released. Because the amount of energy released is very small, measuring these energies requires high-performance measuring devices. Electrical equipment measures either the voltage or the total amount of load transferred during discharge to be able to estimate the energy released by the electric spark initiation process. The standard method for characterizing capacitive discharges of sparks is based on the amount of energy stored.

In order to prevent and eliminate the risk arising from performing these operations, explosion parameters such as ignition temperature, explosion limits, minimum ignition energy, maximum explosion pressure and rate of pressure rise must be determined. The minimum ignition temperature at which a cloud of dust ignites is necessary to prevent the risk of explosion due to the presence of hot surfaces.

The hot surfaces are able to initiate dust clouds existing in industry (ovens, burners, various dryers, enclosures of electrical equipment). In addition, hot surfaces can be generated by overheating of components or mechanical parts of the equipment. 
If an explosive dust cloud is generated in an uncontrolled manner in the proximity of a surface having a temperature higher than the minimum ignition temperature, may result in an explosion of dust. As a consequence, in the dust explosion prevention and fighting, it is important to know the minimum ignition temperature of dust in order to take the necessary measures to ensure that hot surfaces will not exceed this value [3].

Minimum Ignition Temperature (MIT) is the lowest temperature of a hot surface which will generate the initiation and propagation of the dust cloud explosion.

Minimum ignition temperature of a specific combustible dust is defined as the minimum temperature of the air where the flame is observed due to the explosion of dust particles. Minimum ignition temperature evaluation is usually measured by tests described in EN 50281-2-1: 2003.

The ignition temperature is influenced by the size distribution of dust. Some extremely fine powder, can have ignition temperatures so low as should be considered as a pyrophoric powder. Ignition temperature of a single particle is much higher than that of the whole mixture of dust - air, where there are the multiple phenomena of radiation and reflection between neighboring particles [13].

The hot surfaces capable of igniting the dust clouds exist in a variety of situations in industry, such as furnaces, burners, dryers of various shapes, etc. Moreover, hot surfaces can be generated accidentally by overheating of equipment, metal parts. [14]. If a cloud of combustible dust is generated in an uncontrolled manner in the vicinity of a hot surface temperature which is higher than the minimum ignition temperature, the result can be an explosion. It is thus important to know the minimum ignition temperature and to take appropriate measures to ensure that in the area where dust can form a mixture of fuel to avoid this temperature. On the other hand, the minimum ignition temperature is not a constant for a specific cloud of dust, it depends on the geometry and dynamics of the hot surface of the dust cloud [4].

Minimum ignition temperature of dust layer for several organic dust is exemplified in the table no. 2 .

Table 2. The chemical composition of sunflower powder.

\begin{tabular}{|c|c|}
\hline Dust & $\begin{array}{c}\text { Minimum ignition temperature } \\
\text { of dust layer }\end{array}$ \\
\hline Nettle & $260^{\circ} \mathrm{C}$ \\
\hline Buckwheat & $290^{\circ} \mathrm{C}$ \\
\hline Semolina & $400^{\circ} \mathrm{C}$ \\
\hline Cornflakes & $400^{\circ} \mathrm{C}$ \\
\hline Rice flakes & $>400^{\circ} \mathrm{C}$ \\
\hline Flour & $400^{\circ} \mathrm{C}$ \\
\hline Malt & $280^{\circ} \mathrm{C}$ \\
\hline
\end{tabular}

Values of the minimum ignition energy for some combustible powders are given in table no. 3 . 
Table 3. Minimum ignition energy of combustible powders.

\begin{tabular}{|c|c|}
\hline Material & MIE \\
\hline Coal dust & $>1000 \mathrm{~mJ}$ \\
\hline Flour & $300-1000 \mathrm{~mJ}$ \\
\hline Sugar & $10-30 \mathrm{~mJ}$ \\
\hline Aluminium powder & $100-300 \mathrm{~mJ}$ \\
\hline Sunflower dust & $30-100 \mathrm{~mJ}$ \\
\hline Flour & $300-1000 \mathrm{~mJ}$ \\
\hline
\end{tabular}

In this paper were performed tests to evaluate the minimum ignition temperature of dust layer, minimum ignition temperature of dust cloud and to determine the minimum ignition energy for sunflower husks dust.

\section{Materials and methods}

Minimum ignition temperature of a dust layer is the lowest temperature of a hot surface at which a layer of dust with a specified thickness is ignited deposited on this hot surface. In determining the minimum ignition temperature in the layer SR EN 50281-2-1: 2002 was used (method A, B) Method A, was applied to determine the minimum temperature at which the dust layer located on a heated oven plate undergoes thermal decomposition and ignites [15]. The method refers in particular to industrial equipment with hot surfaces in which dust creates layers of different thicknesses that pose a danger to air contact. According to standard EN 50281-2-1: 2002 (method A), the ignition of the powder in the layer can be recorded when[22]:

a) there is a bright or burning flame, or

b) the measured dust temperature has reached $450{ }^{\circ} \mathrm{C}$ or,

c) the measured dust temperature exceeded by $250 \mathrm{~K}$ the temperature of the oven plate.

Method principle: The method is applicable to the determination of the minimum temperature of a specified hot surface which causes a layer of dust with a specified thickness deposited on that surface to decompose and / or ignite. The samples were prepared so as to be homogeneous and representative of the dust received for analysis. The dust sample was placed on a heated surface, consisting of a metal plate $[15,16]$. The plate is electrically heated and the temperature is controlled by means of a device whose sensitive element is a thermocouple mounted in the plate, near the center and with hot welding at not more than $1 \pm 0.5 \mathrm{~mm}$ from the upper surface and in good thermal contact with the plate. The test is performed until it is found either visually or based on the registration of the thermocouple that the layer has ignited, or that it has self-heated without ignition. The equipment used to determine the minimum ignition temperature of the combustible dust cloud is presented in figure no. 1 


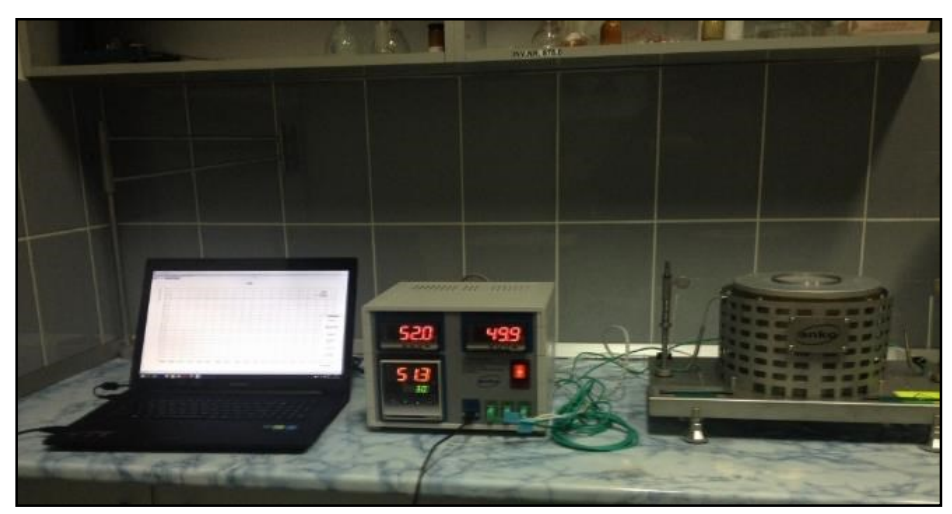

Fig. 1. Apparatus for determining the ignition temperature of the combustible dust layer

Ignition temperature of a dust cloud is the lowest temperature of the hot inner wall of an oven that causes a cloud of dust to ignite in the air inside it [17,18]. Principle of the method: The method is applicable to the determination of the minimum temperature of a specified hot surface which causes the ignition of a cloud in a given sample of dust or other solid particles [19]. As the operation of the oven requires short periods of dust particles inside, this method is applicable to industrial equipment where dust is present in the form of a cloud for a short period. Place the dust sample in the sample holder, set the oven temperature between $500^{\circ} \mathrm{C}-1000^{\circ} \mathrm{C}$ and the relative air pressure in the tank at $10 \mathrm{kPa}$ (0.1bar) [20]. Scatter the dust in the oven and see if it ignites or not. The minimum ignition temperature shall be recorded as the lowest oven temperature at which the ignition was obtained with the specified procedures, minus $20 \mathrm{~K}$ for oven temperatures above $300{ }^{\circ} \mathrm{C}$ and minus $10 \mathrm{~K}$ for oven temperatures equal to or less than $300^{\circ} \mathrm{C}$ [21]. In order to determine the minimum ignition temperature of the dust cloud, method $\mathrm{B}$, the oven is programmed to a preset temperature, the test equipment connected to it was applied. The method is used for industrial equipment, inside which dust clouds can form for a short time. The furnace is represented by a vertical pipe furnace, generally known in the literature as the GodbertGreenwald furnace. The tubular oven is mounted in an upright position and its lower end is open to the atmosphere. The desired temperature is set using a device that controls the oven temperature. At the bottom of the oven is a stainless steel mirror that allows visual monitoring of the inside of the tubular oven. In order to comply with the requirements of the regulations, the dust is screened and the fraction must be below $71 \mu \mathrm{m}$. The equipment used to determine the minimum ignition temperature of the combustible dust cloud is shown in figure no. 2 .

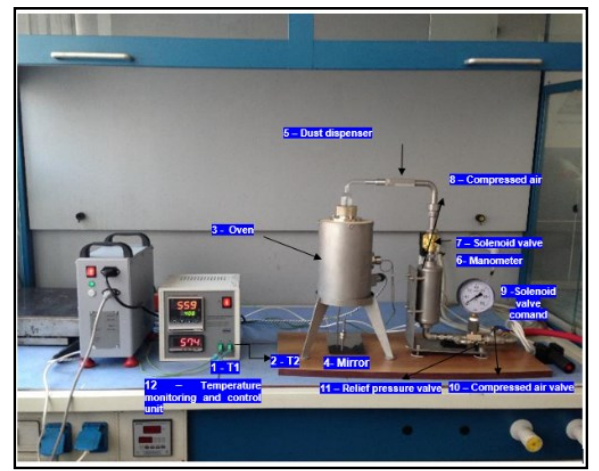

Fig. 2. Apparatus for determining the ignition temperature of the combustible dust cloud 
The determinations of the minimum ignition energy (MIE) were performed in accordance with SR EN ISO / IEC 80079-20-2 / 2016, with the experimental stand from fig. no. 3 .

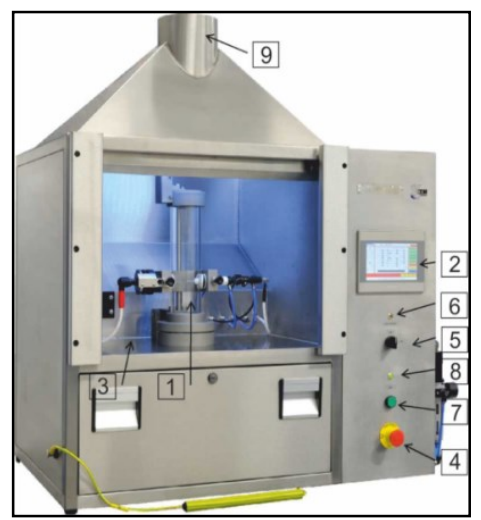

Fig. 3. Stand for igniting the explosive dust / air atmosphere by capacitive electrostatic discharges

The dust stored at the base of the stand tube for igniting the explosive dust / air atmosphere by capacitive electrostatic discharges was made and consists of seven basic units:

1. Hartmann glass tube with its handling system;

2. High voltage unit;

3. Dust dispersion system;

4. Electronic and pneumatic control unit;

5. Control panel with "touch screen";

6. Stand case;

7. The personal computer together with the software used

The stand is connected to a screw compressor that provides compressed air with a pressure of at least 7 bar. In accordance with the requirements in addition to the basic units, the stand also includes the air compressor, thermo-balance, analytical balance and anaerobic chamber (glove-box), and the recommendations of the ISO / IEC 800079-20-2 standard, dust dispersion and initiation 1 -The mixture takes place in a Hartmann tube with a capacity of 1.2 liters. The electrostatic discharge is generated in the high voltage unit. The unit consists of a high voltage source, a set of internal capacitors, a high voltage switch, a discharge circuit, high voltage electrodes and programmable electro-pneumatic valves (PLC), which communicate with the operator through the control panel with "touch screen".

\section{Results and discussion}

The sunflower husks dust is presented in the fig. no. 4 .

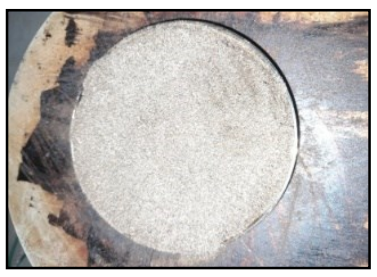

Fig. 4. Sunflower husks waste sample image 
The minimum ignition temperature for dust layer determined for the waste resulting from the sunflower husks was $270{ }^{\circ} \mathrm{C}$ and the minimum ignition temperature for the dust cloud was $520^{\circ} \mathrm{C}$ and the minimum ignition energy was between $30 \div 100 \mathrm{~mJ}$.

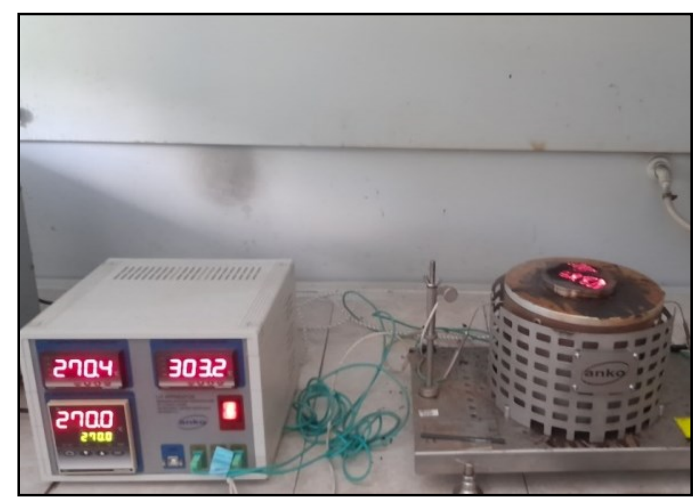

Fig. 5. Minimum ignition temperature for sunflower husks dust

Dust and dust that form in the production processes that form after the processes of sedimentation and settling in the layer, can be heated and can be subjected to self-ignition through contact that may occur with heated surfaces, machinery and equipment.

Fires can occur in layers of combustible dust after intimate contact with hot surfaces after the initial occurrence of the phenomenon of smoldering, incandescence.

Analyzing the data from the literature the values obtained in the case of waste of sunflower seed husks the temperatures and the minimum ignition energy obtained are less than other combustible dusts which means that the protective measures that should be taken in the technological process must be correlated with these parameters.

The value of the minimum ignition energy of sunflower dust is determined is between $30-100 \mathrm{~mJ}$, this value is quite small if we compare it with the minimum ignition energy of coal dust (over $1000 \mathrm{~mJ}$ ) or flour which is between 300 and $1000 \mathrm{de} \mathrm{mJ}$.

\section{Conclusions}

Analysis of the minimum ignition temperatures of the dust layer and the minimum ignition temperatures of the dust cloud indicates that there is a risk of fire / explosion in the case of sunflower husks. Sunflower husks are used as production materials for heating, making pellets for heating. As an ecological substrate used in the production of heat and electricity, due to the low value of the minimum ignition temperatures it confers a higher risk of fire and explosion during transport and pneumatic loading in the case of existing power plants. Agricultural waste is used for the production of pellets for heating.

The minimum ignition energy of sunflower dust is determined to be between $30 \div 100$ $\mathrm{mJ}$, this value is quite low when compared to the minimum ignition energy of coal dust (over $1000 \mathrm{~mJ}$ ) or flour which is between 300 and $1000 \mathrm{~mJ}$.

Analyzing the ignition temperature of agricultural waste from sunflower, it can be concluded that the values determined the minimum ignition temperature in the layer is 270 ${ }^{\circ} \mathrm{C}$, being a fairly low value compared to other organic substances from plants. 


\section{References}

1. Center for Chemical Process Safety (CCPS), Guidelines for Safe handling of Powders and Bulk Solids, AIChE/CCPS, New York (2005)

2. R.Eckhoff Dust Explosions in the Process Industries, 3rd Ed. Gulf Professional Publishing, Houston, TX (2003)

3. Investigation Report: Combustible dust hazard study, Report no. 2006-H-1(2006)

4. OSHA, Hazard Alert: Combustible Dust Explosion (2014)

5. OSHA, Hazard Communication Guidance for Combustible Dusts (2009)

6. SR EN 14034-1:3 Determination of dust cloud explosion characteristics. Determination of presumptions. Determination of maximum explosion pressure rise values and determination of the lower limit of dust clouds, EN Standard (2011)

7. W.Bartknecht, Explosions, (Springer-Verlag, Berlin, Heidelberg,New York 1981)

8. P.R.Amyotte, M. J Pegg, F. I., Khan F., M.Nifuku, T Yingxin J.of Loss Prev. 20, (2007)

9. I Tureková., I. Marková , Appl. Sci., 17, 10 (2020)

10. Horvath J., Balog K-Res. Pap, Slovak University of Technology Bratislava Spec., Numb., (2013)

11. M Polka., Z Salamonowicz, M.Wolinski, B Kukfisz ., Proc. Eng. 45 (2012)

12. J.M. Jones, A. Saddawi, B. Dooley, E.J.S. Mitchell , J. Werner, D.J. Waldron, S. Weatherstone, A. Williams e-Fuel Proc, Tech., 134 (2015)

13. Polin I.,Zhengrong G.,Humber D., Dalsted K., Industr.Crops and Prod., 50 (2013)

14. Hasseinradeh S., Norman F., Verplaetsen F., Berghman I., Van den Bulck E.,J. of Loss Prev. in the Proc. Ind. Vol. 36 (2015)

15. Taveau J.,Lemkowitz S., Hochgreb S., Roekaerts D.Process Safety Progress AIChE 38 (2018)

16. Combustible dusts \&Explosive Atmospheres a Guide by OHSA (2021)

17. E.Danzi, L.Marmo, D.Riccio. J. of Loss Prev. in the Proc. Ind., 36 (2015)

18. M. Polka Open Access Journ. Vol. 10 (2020)

19. C. Huang, S. Shy, C. Liua, Y. Van, Proceed. of the Combust. Instit.1 (2007)

20. R. Ono, M. Nifuku, S. Fujiwara, S. Horiguchi, T. Oda, J. of Electrostatics, 65 (2007)

21. SR EN ISO/IEC 80079-20-2 /2016 Explosive atmospheres -Part 20-2 :Material characteristicsCombustible dust test methods (2016)

22. EN 50281-2-1: 2002- Methods for determining the minimum ignition temperatures of dust (Method A) (2002) 